\title{
A Structural Equation Model for the Evaluation of the Switching Costs of Information Communication Technology in SMEs
}

\author{
Edzai Kademeteme and Hossana Twinomurinzi \\ School of Computing, University of South Africa, UNISA Science Campus, Florida Park, Roodepoort, \\ South Africa \\ eamkademeteme@gmail.com \\ twinoh@unisa.ac.za
}

DOI: 10.34190/EJISE.19.22.2.004

\begin{abstract}
Most evaluation methods for purchasing newer and enticing information and communication technology (ICT) in organisations are based on financial models, or are premised on the presumption that the new ICT is not replacing an existing ICT. However, the availability and constant proliferation of more powerful and functional ICT in most organisations today means that the models may need to recognise already existing ICTs in use. There is therefore a need for such a tool that can assist decision makers, particularly in Small to Medium Enterprises (SMEs). Using the Information Systems Success Model as the base model, the study developed a conceptual framework using financial and non-financial models. Data collected from 222 SME owners using an online survey was analysed using Structural Equation Modelling (SEM). The key findings suggest that the psychological views of SME owners and the performance of the existing ICTs are important in the evaluation of existing ICTs. The study found that some features of the existing ICTs and SME surroundings do not matter, but the contentment of the SME owner with the existing ICTs does. This study is expected to assist SME owners with the creation of a handy tool to evaluate existing ICTs before considering newer enticing ICTs. The study recommends that SME owners should not base their decisions to continue using the existing ICTs on their personal experiences only. Future research, however, should consider other factors which may be relevant in the evaluation of existing ICTs.
\end{abstract}

Keywords: Information and Communication Technology, evaluation, Small to medium enterprises, information system, financial models, Structural Equation Modelling, adoption, decision making, decision maker.

\section{Introduction}

Changes in information and communication technology (ICT) innovations have become a norm. Some of the changes are crucial as they cater for addressing new business challenges and enhancing productivity even at the national level (Xiao et al., 2013). It is important therefore, that organisations are articulate in how best they can incorporate the changes that ICT innovations bring. Given the ever-faster pace at which ICT innovations are evolving, organisations are enticed to make decisions to adopt the innovations, or to upgrade their systems, to merge the changes, or to neglect the changes and continue using the existing ICT. These options have sometimes left decision makers in organisations frustrated, as they have a critical decision to make. This paper is centered on Small and Medium Enterprises (SMEs) in South Africa.

The pace at which ICTs are innovating has an influence on SMEs in their effort to remain competitive. SMEs could have benefitted if there existed a tool or framework that could assist SME owners who are usually the overall decision makers, in making an informed decision when they are at the verge of switching from an existing ICT to adopt an emerging ICT. Therefore, this papers' objective is to develop a framework that can assist SME owners in the evaluation of an existing ICT before adopting and switching to an emerging ICT.

Literature suggests that most organisations use financial models such as Return on Investment (ROI), Account Rate of Return (ARR), Payback Period (PBK), Net Present Value (NPV), Internal Rate of Return (IRR) and Real Option Value (ROV) to evaluate the value of an ICT investment (Chaysin et al., 2016). On the other hand, others have used non-financial models such as Updated Information Systems Success Model (ISSM), Theory of Planned Behavior (TPB), Technology Acceptance Model (TAM) and Unified Theory of Acceptance and Use of Technology (UTAUT). With the ISSM model as the base model, the paper therefore, reviewed the popular financial and non-financial models in order to come up with an integrated framework that can assist SME owners in the evaluation of existing ICT before switching to an emerging ICT. Specifically, the paper sought to answer the following primary research question; what is an appropriate tool that can be used by South African SMEs to evaluate existing ICTs before adopting new enticing ICTs?

Reference this paper: Kademeteme, E., and Twinomurinzi, H., 2019. A Structural Equation Model for the Evaluation of the Switching Costs of Information Communication Technology in SMEs. The Electronic Journal of Information Systems Evaluation, 22(2), pp. 113-127, available online at www.ejise.com 
The rest of the paper is organised as follows: The next section presents a discussion of the related theories. It is followed by the research methodology. The next section presents the analysis, findings and results. The final section offers inferences, conclusion and areas for further research.

\section{Related theoretical background}

The study reviewed both financial and non-financial models.

For the non-financial models, it reviewed the updated Information Systems Success Model (ISSM) developed by DeLone and McLean (DeLone and McLean, 2002). ISSM was adopted as the base model because literature has shown that this model has been successfully and prominently used in the area of ICT evaluation (Bernroider, 2008, Gable et al., 2008, McGill et al., 2003, Petter et al., 2008, Petter and McLean, 2009, Wang and Liao, 2008). The ISSM model was supported by the following theories; Theory of Planned Behavior (TPB) developed by Ajzen (1991), Technology Acceptance Model (TAM) developed by Davis (1989) and Unified Theory of Acceptance and Use of Technology (UTAUT) developed by Venkatesh et al. (2003). These models were reviewed in order to gather the non-financial factors that would assist in the evaluation of the nonfinancial value of an ICT.

The financial value of existing ICTs was considered using the following models Return on Investment (ROI), Account Rate of Return (ARR), Payback Period (PBK), Net Present Value (NPV), Internal Rate of Return (IRR) and Real Option Value (ROV). These models were considered because literature suggests them as the most common and popular financial evaluation models (Chaysin et al., 2016).

The reviewed financial and non-financial factors were then triangulated into an integrated technology evaluation model. The following section details the review of non-financial and financial factors respectively.

\subsection{Non-financial Models}

The updated ISSM states that, information, system and service quality, (intention to) use and users (SME Owner in this study) satisfaction are the predictors of net benefits of using ICT (Delone and McLean, 2003). If one has to evaluate the success of an ICT then information, system, and service quality are the characteristics that affect subsequent use or intention to use and SME Owner satisfaction which in turn results with positive or negative benefits which will recursively determine further use of the ICT. It is imperative to note that, the ISSM focuses more on the exploration of the user satisfaction (by measuring information and service quality) and the system performance (by measuring system) but is silent on other important factors such as environmental, technological characteristics, social, and financial factors. According to Lyytinen and Ngwenyama (1992), many ICT applications have focused on the individual's task productivity while underestimating the importance of the social context and this has led to inappropriate application designs, difficulty of use, and outright failure of many systems. Therefore, this paper puts the social and environmental context of ICT use into consideration.

Furthermore, Orlikowski and lacono (2001) noted that IS researchers have treated ICT as a single, stable, discrete, independent, standalone and fixed investment. This has caused organisations to replace the whole existing ICT when it is not the whole ICT artefact that should be replaced but rather one or two components that make up that ICT. Bidgoli (2011) Acknowledges and identifies that an ICT is not necessarily a single and discrete technology but it consists of various components such as; people, data, information, hardware, software, database and network. Therefore, this paper will address the system factor in ISSM as composed of the aforementioned components which will be measured independently.

It is important to note that, the ultimate decider of whether an existing ICT is still valuable or not is the day-today user of the ICT; hence it is vital to investigate the SME Owner perceptions on the evaluation of the existing ICT. Cronje (1990) and Geisler (1999), puts it that understanding technology by its existence alone is impossible, but only within the context of its use by people, organisations, and society. ICT is not defined and evaluated by what it is, but by its actual and potential users (Cronje, 1990, Geisler, 1999). Evaluation of existing ICT thus depends on the characteristics of the SME Owners amongst other factors. To gather the SME owner perceptions, the study reviewed the TAM, TPB and UTAUT. 


\subsubsection{Unified Theory of Acceptance and Use of Technology}

TPB, TAM and UTAUT were developed to measure subsequent usage of an IS being driven by user intentions or perceptions towards the IS. UTAUT was developed by Venkatesh et al. (2003) through a review and consolidation of eight models that earlier research had employed to explain IS usage behavior. UTAUT reviewed the following theories; theory of reasoned action, technology acceptance model, motivational model, theory of planned behavior, a combined theory of planned behavior/technology acceptance model, model of PC utilization, innovation diffusion theory, and social cognitive theory. The purpose was to point out similarities of various factors in these models and then consolidate them into a single detailed model. In order to avoid repetition of work that has been over researched, the consideration of UTAUT model in this study implicitly recognizes the other eight models that were consolidated into the UTAUT model, since it intended to get rid of the short falls in each of the eight models by adopting the strength of each model into a single unified model. Therefore, this paper will not review explicitly the TPB and TAM. Conclusively, UTAUT summarized the eight models into four direct determinates (performance expectancy, effort expectancy, social influence, and facilitating conditions) of ICT usage intention and behaviour.

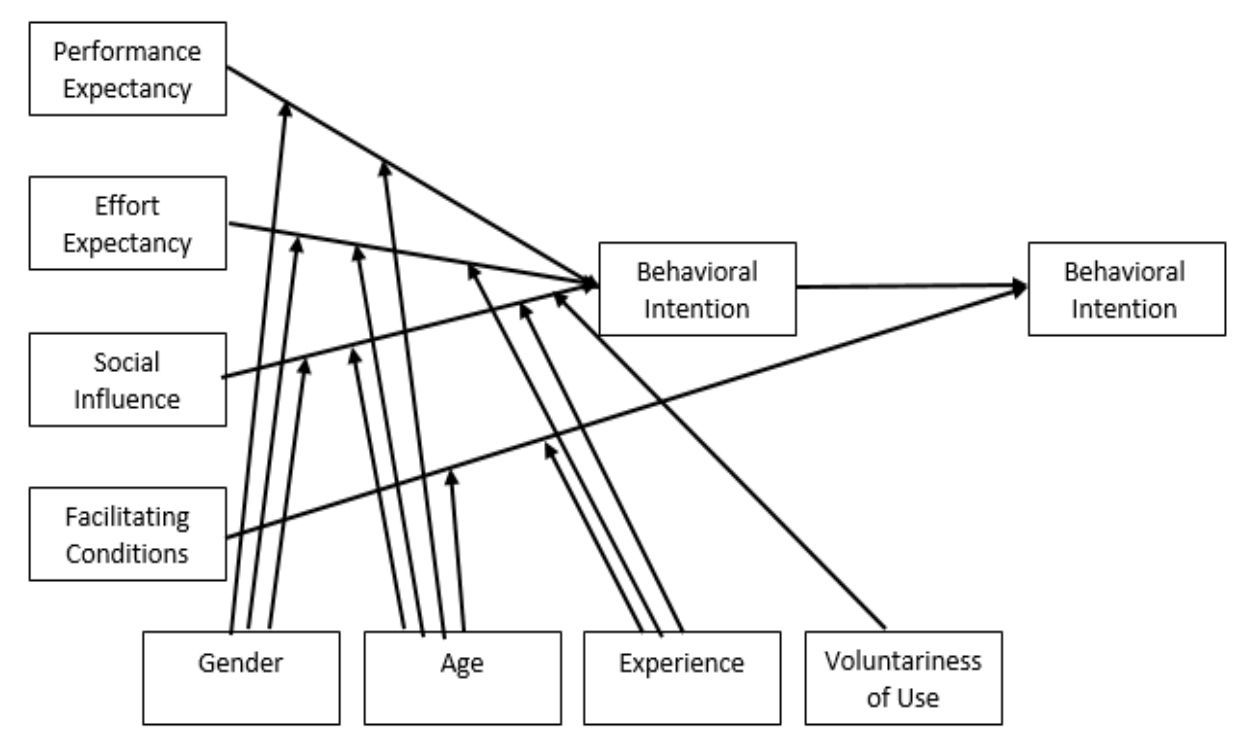

Figure 1: Unified Theory of Acceptance and Use Technology (UTAUT) (Venkatesh et al., 2003)

The eight models were distilled into four direct determinates (effort expectancy, performance expectancy, facilitating conditions and social influence) of ICT usage intention and behaviour. Diagrammatically, UTAUT model is shown in figure 1 . The consideration of the UTAUT model as a potential base model to inform this study implicitly recognises the eight models consolidated into the UTAUT model. The final model intended to eliminate the short falls in each of the eight models by adopting the strength of each model into a single unified model. Originally, the UTAUT model was developed for the purpose of explaining user intentions to use and subsequent technology usage behaviour (Venkatesh et al., 2003). Several research studies (Alwahaishi and Snásel, 2013, Foon and Fah, 2011, Im et al., 2011, Maillet et al., 2015, Oliveira et al., 2014, Oye et al., 2014, Pardamean and Susanto, 2012, Tan, 2013, Yu, 2012, Zhou et al., 2010) have used UTAUT to explain users' acceptance, adoption and use of ICT. Other studies (Roca et al., 2006, Zhou, 2011) have used it to investigate the effectiveness of ICTs by investigating the continual usage of ICTs. Although the measure of ICT effectiveness is closely related to evaluation of ICTs, its value does not imply evaluation of ICTs.

Just like TAM, UTAUT was developed to measure the adoption, use and acceptance of emerging ICTs. Factors like effort and performance expectancy thus refer to user expectations regarding the system which is to be adopted. However, when dealing with a system that users have already experienced, these expectations become reality and users' experience. We thus try to define the constructs of UTAUT as they were originally defined by Venkatesh et al. (2003). The study then goes a step further by re-defining these same constructs in the context of this research.

Towards the evaluation of existing ICTs, the constructs of UTAUT may be explained as follows: 
1. Social influence is the degree to which an individual perceives that other significant people believe he/she should use the existing ICTs (Venkatesh et al., 2003). Previous studies (Ajzen, 1991) even though referred social influence as subjective norm they defined it as the perceptions that an individual possess with regards to what other people important to them think of their behavior. These two definitions agree. The opinion of any given significant other is weighted by the motivation that an individual must comply with the wishes of that significant other. Hence, overall subjective norms can be expressed as the sum of the individual perceptions and motivational assessments for all relevant significant others. This is justified by Park et al. (2007) who advocated that the effect of subjective norms is noticeable in mandatory settings (influenced at organisational level) where other people's opinions matter more to the inexperienced than in voluntary settings (influenced at individual level). Mandatory settings place social pressure on an individual to follow specific guidelines. In voluntary settings one can decide what is needed. Later studies referred to the subjective norm as social Influence (Bandura, 1986, Park et al., 2007, Venkatesh et al., 2003) and social factors (Thompson et al., 1991). In this study subjective norm, or social influence, will be referred to as social factors.

Regarding this study, the perceptions of the significant other on the evaluation of existing ICTs must be considered. It is important to note that the perceptions held by the significant other do not directly influence the evaluation of existing ICTs. They do, however, exert influence through the perceptions held by individuals. The current study hypothesises that social factors will influence user behaviour which will then impact on the evaluation of ICTs.

2. Effort Expectancy as defined by Venkatesh et al. (2003) is the degree of ease of use of the system. In TAM Effort expectancy is explained as perceived ease of use (Davis, 1989). It is a pre-condition which measures the degree of anticipation an SME owner exhibits before he/she uses a system. This study purposes to investigate the effort that SME owners have experienced with the existing ICTs. Therefore, in relation to this study, effort expectancy is going to be termed effort experience as it purposes to investigate the degree of ease of use experienced in using the existing system. In this regard, effort experience is related to SME owners' self-evaluation of how stress-free and easy it is to complete tasks with the use of existing ICTs. Generally, SME owners are attracted to ICTs which they have experience of and which consequently requires less effort to use. The effort experience construct relates to the complexity of the ICTs. The more complex the ICTs are, the more effort the SME owner must exert to accomplish a task.

However, it is important to note that any system requires substantial effort to navigate in its early stages of adoption. However, as the user increasingly interacts with the ICTs, the time and effort required by the SME owner becomes less. The study theorises that the more experience the SME owner has with using the ICT, the less effort he/she requires to use the system. This theory is driven by the fact that, as experience increases, the SME owner becomes increasingly familiar with which avenues and short cuts to access or request help and support within the organisation concerning the ICT (Venkatesh et al., 2003) as well as the organisation's trends and tendencies of adopting emerging ICTs or evaluating existing ICTs.

3. Performance Expectancy as defined by Venkatesh et al. (2003) is the degree to which a user believes that using the system will help him/her achieve better job performance. Other studies have referred to performance expectancy as usefulness and job-fit (Thompson et al., 1991), while Davis (1989) referred to performance expectancy as perceived usefulness. Performance expectancy is a precondition as it measures the anticipated performance of the SME owner before he/she uses, or experiences, the system. This study purposes to investigate ICTs that are already being used. Therefore, performance expectancy will be termed performance experience, as it intends to investigate the opinions of SME owners as far as their performance experienced with the system is concerned. Performance experience is the degree to which an SME owner has experienced in his/her job using the existing ICTs. Performance experience will have an impact on behaviour and attitude towards existing ICTs.

4. Facilitating conditions according to Venkatesh et al. (2003) is the degree to which an individual believes that technical and organisational infrastructure exist to support the use of existing ICTs. In 
their study, Venkatesh et al. (2003) hypothesised, tested and found, that facilitating conditions will not have an influence on behavioural intention when effort expectancy and performance expectancy are present. They empirically concluded that facilitating conditions will have a direct impact on ICT usage. Based on the definition by Venkatesh et al. (2003), facilitating conditions thus relate to the characteristics of the organisation which are termed organisational factors in this study. In this study we hypothesise, that organisational factors will directly influence evaluation of existing ICTs.

According to Cronje (1990), ICT in its totality consists of: technology, organisation, people and society, as well as all the relationships between these elements. Optimisation of the total system therefore implies the optimisation of the whole ICT and not its individual elements (Cronje, 1990). Thus there is need to consider the whole ICT artefact in the evaluation process. Therefore, apart from social context (social factors) and people (individual factors) this study will further investigate the impact of organisational factors on the evaluation of existing ICTs. Organisational factors play an important role on the evaluation of ICTs as they exert pressure on one another which leads to the creation of a competitive, turbulent environment (Teece et al., 1997, Wang and Ahmed, 2007). These pressures are thus exerted on the day to day users of ICTs. The environment in which the organisation operates moderates organisational factors.

Therefore, the study hypothesises that:

H1: Social factors will impact on behavioural Intention to continue using existing ICTs.

H2: Effort experience will impact on behavioural Intention to continue using existing ICTs.

H3: Performance experience will impact on behavioural Intention to continue using existing ICTs.

H4: Organisational factors will directly influence evaluation of existing ICTs.

\subsubsection{DeLone and McLean Information Systems success model}

The information systems success model was initially developed by DeLone and McLean (1992) for the purpose of measuring IS success. Immediately after its development, IS researchers (Jiang et al., 2002, Pitt et al., 1995, Seddon, 1997) began proposing modifications to this model. Ten years later Delone and McLean (2003) embraced some of the changes suggested by the aforementioned researchers and consequently updated their old model to the Updated DeLone and McLean IS Success Model (ISSM). They responded by adding service quality and expanding the use construct to use and intention to use

ISSM states that service, system, information and quality, (intention to) use and SME owner satisfaction are the predictors of net benefits of using ICTs. The researchers further argue that if one must evaluate the success of ICTs then service, system, information and quality are the characteristics that affect its subsequent use, or intention to use. SME owner satisfaction, in turn, results in positive or negative benefits which will determine further use of the ICTs. DeLone and McLean (2002) and Delone and McLean (2003) came up with ISSM after a review of the existing definitions of IS success and their corresponding measures. This led to a categorisation of these measures into the aforementioned predictors of net benefits (Delone and McLean, 2003) instead of individual and organisational impact (DeLone and McLean, 1992). Figure 2 summarises the ISSM.

ISSM focuses on the exploration of user satisfaction (by measuring information and service quality) and the system performance (by measuring system) but does not comment on other important facets such as environmental and social factors. According to Lyytinen and Ngwenyama (1992), many ICT applications have underestimated the significance of social context while focusing more on the individual's task productivity. This has led to unfitting application designs, user difficulties and the absolute failure of many systems. ISSM is not exclusive to this conundrum as it measures IS success in terms of SME owner satisfaction while explicitly neglecting other components of an information system (IS) such as hardware, software, network and social context. The framework lacks some crucial factors that influence the effective evaluation of ICTs. The current research study sought to address this gap through its investigation of environmental, technological characteristics, social and financial factors that may influence the evaluation of ICTs. 


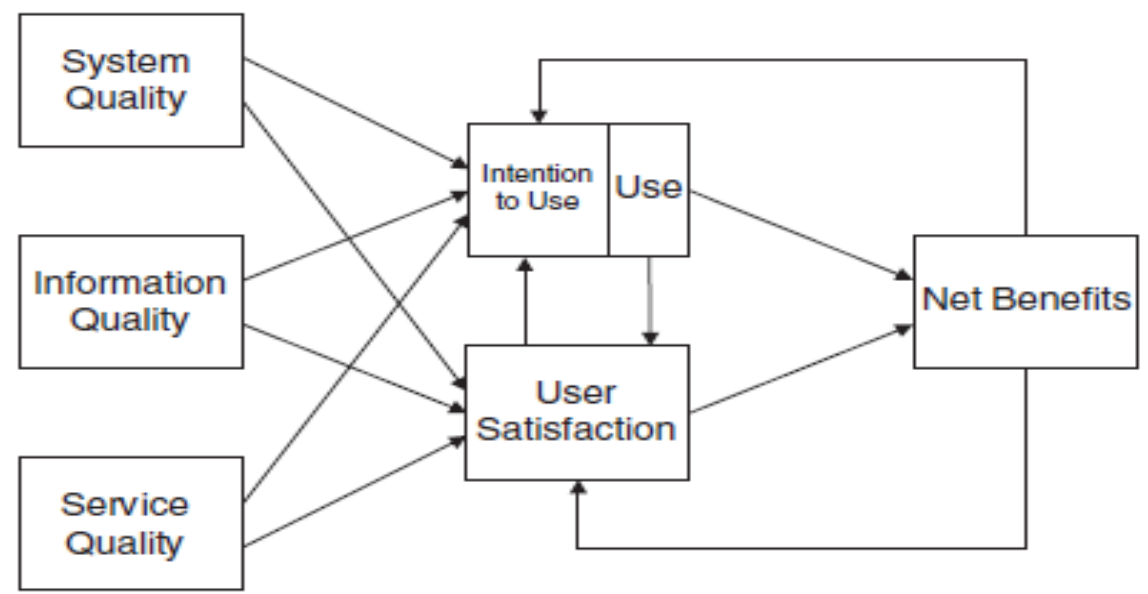

Figure 2: Updated DeLone and McLean IS success model (ISSM) (Delone and McLean, 2003)

The ultimate indicator as to whether ICTs are still valuable lies with the day-to-day user. It is thus vital to investigate the SME owner's perceptions regarding the evaluation of existing ICTs. Geisler (1999) and Cronje (1990) posit that technology needs to be viewed within the context of its use by people, organisations and society and that it is thus impossible to understand technology in isolation. Evaluation of existing ICTs thus depends on the characteristics of SME owners, amongst other factors. This supports one of the sub-objectives of this study namely incorporating the SME owner's perceptions and characteristics in the evaluation process.

DeLone and McLean (2002) and Delone and McLean (2003) measured IS success based on the level of user satisfaction. User satisfaction is a derivative of information, system, service quality and intention to use (DeLone and McLean, 2002, Delone and McLean, 2003). Many research studies (Ajzen, 1991, Davis, 1989, Venkatesh et al., 2003) have been conducted as to the nature of user satisfaction. These studies measured user behaviour as a precursor to the continued use of an IS. Ajzen (1991) asserted that individual behavior or actions (continued use of an existing ICT) is determined by intentions to act and, in turn, intentions to act were determined by an individual's attitude towards the action, the subjective norms surrounding the action and the individual's perception of the ease with which the action or behaviour can be performed. Venkatesh et al. (2003) enhanced the models by Ajzen (1991) and Davis (1989) and also asserted that behaviour intention is predicted by social factors, effort expectancy and performance expectancy. The researchers (Ajzen, 1991, Davis, 1989, Davis, 1993, Venkatesh et al., 2003) were measuring behaviour which may be equated to adoption, usage or acceptance. However, other researchers (Bokhari, 2005, Cheah et al., 2014, Cornacchia et al., 2008, Kalema, 2013, Ling et al., 2011, Nirban, 2014, Noorman et al., 2007, Trimmer et al., 2008) have manipulated the dependent variable and equated it to IS effectiveness or effective usage.

In their study Delone and McLean (2003) defined their model metrics as:

1. System quality describes the characteristics or features of an IS. Examples of system quality attributes are: system flexibility, ease of use, response times, ease of learning, flexibility, system reliability and sophistication.

2. Information quality describes the characteristics or features of the system outputs (processed data) such as dashboards or reports. Examples of attributes under information quality are: timeliness, completeness, currency, accuracy, relevance, conciseness, understandability and usability.

3. Service quality describes the quality of the support that users receive from the IT support personnel or ICT department. Examples of attributes under this construct are: technical competence, responsiveness, empathy of the personnel staff, reliability and accuracy. In this study service quality will be termed organisational factors.

4. Intention to use ICTs refer to the attitudes toward the ICTs (DeLone and McLean, 2002). Intention to use ICTs influence the behaviour of the individual towards the ICTs (Davis, 1989, Davis, 1993, Venkatesh and Morris, 2000, Venkatesh et al., 2003). The behaviour of an individual is considered an act such as actual ICT usage, ICT acceptance and ICT adoption (Davis, 1989, Davis, 1993, Venkatesh and Davis, 2000, Venkatesh et al., 2003). These intentions will determine continual usage of the system. 
5. System use refers to the manner and degree in which end users utilise the capabilities of an IS. Examples of attributes that measure this construct are: nature of use, extent of use, amount of use, appropriateness of use, frequency of use and purpose of use. Intention to use is an attitude whilst use designates a behaviour (DeLone and McLean, 2002). Behavioural intentions to use predict the actual behaviour of a user (Ajzen, 1991, Davis, 1989, Davis, 1993, Venkatesh and Davis, 2000, Venkatesh et al., 2003). In the case of investigating existing ICTs already in use, behavioural intention to use becomes behavioural intention to continue using. Therefore behavioural intention to continue using will influence SME owner satisfaction and ICT evaluation.

6. User satisfaction relates to level of users' satisfaction with the information (output) from the IS. User satisfaction and behavioural intention to continue using have a cause and effect relationship (Delone and McLean, 2003). SME owner satisfaction will determine the evaluation of existing ICTs.

7. Net benefits measures the success of nations, industries, organisations, groups and individuals as conveyed by an IS. Examples of such benefits include: improved competitive advantage, cost reductions, improved productivity, creation of jobs, consumer welfare, increased sales, improved profits, better decision making, market efficiency and economic development.

Based on definitions of the ISSM metrics, as well as the way in which they have been applied by researchers, this study proposes that system quality and information quality describe the technological characteristics. This proposition is reinforced in a study conducted by Orlikowski and lacono (2001) in which they advocate that the ICT artefact be theorised. Their study observed that IS researchers failed to appreciate and acknowledge the ICT artefact in their studies. They noted that the ICT artefact tends to disappear from view, is often taken for granted or is presumed to be without a hitch once it has been built and installed. This observation suggests that IS studies have not explored ICT components independently but that they have conceptualised these artefacts as relatively independent, discrete, stable and fixed (Orlikowski and lacono, 2001).

The ICT artefact is made up of various components including hardware, software, databases, information and network components (Bidgoli, 2011). Organisations might believe that they need to replace the whole ICT artefact when adopting emerging ICT when, in actual fact, only the network is slow or a virus has affected the software component of the artefact. In such a scenario, it is more viable to replace the faulty component than replace the entire ICT artefact. Therefore, it is important to identify the precise problem with the existing ICTs before replacing it with new enticing ICTs. Such a thorough investigation (evaluation) will eventually lead to an informed decision.

This study will therefore expand the system quality metric of the ISSM into the various components which make up an ICT: namely hardware, software, database, information, network and cloud computing. Together with information quality, these metrics describe the technological characteristics of the existing ICTs being studied. Service quality describes the role an organisation plays in supporting the use of the existing ICTs. Service quality will be incorporated into organisational factors.

Therefore, this study hypothesises the following for existing ICTs:

H5: Technological characteristics will influence effort experience.

H6: Technological characteristics will influence performance experience.

H7: Effort experience will impact on user satisfaction.

H8: Performance experience will impact on user satisfaction.

H9: Behavioural intention to continue using existing ICTs will influence user satisfaction.

H10: Behavioural intention to continue using the existing ICTs will influence evaluation of existing ICTs.

H11: User satisfaction will influence behavioural intention to continue using existing ICTs.

H12: User satisfaction will influence evaluation of existing ICTs. 


\subsubsection{Environmental Influence}

Organisations are forced to react to, and within, the competitive and volatile environment (Teece et al., 1997, Wang and Ahmed, 2007). The way in which an organisation reacts to environmental pressures will influence its verdict regarding existing ICTs. According to Odhiambo (2016), environmental pressures refer to factors outside the organisation which influence the SME's ability to function. Many firms have opted to adopt practices in order to stay ahead of competitive pressures in their industries (Odhiambo, 2016). According to Kim et al. (2017), environmental influences, or factors, include a competitive environment and external support for the use of ICTs. This study hypothesises that:

H14: Environmental factors will impact on organisational factors.

\subsection{Financial Evaluation Models (FEM)}

Several financial evaluation models (FEM) have been used for the evaluation of ICT investment. These includes ROI, ARR, PBK, NPV, IRR and ROV (Chaysin et al., 2016). Of these models, the most popular one is PBK (Lefley, 2013). However Chaysin et al. (2016) and Lefley (1996) put it that PBK only measures the risks associated with a project but does not measure the time value of money concept of any investment. This has therefore made PBK lose its popularity and paved way for other simple methods such as NPV (Chaysin et al., 2016, Lefley, 1996, Milis et al., 2009) as it puts into consideration the time value of money. However, because risks of projects are common among ICT projects and again as they are still crucial to personnel, organisations have decided to apply multiple methods to a project (Chaysin et al., 2016). The proper role of PBK is as a supplement to profitability measurements and that PBK has been widely used as a secondary measurement usually linked with a more sophisticated method such as NPV respectively (Lefley, 1996, Rappaport, 1965). Therefore, this paper used both PBK and NPV to evaluate the financial value of an existing ICT. The overall evaluation will influence the SME directly as either to keep using the existing ICT or to adopt and switch to an emerging ICT. According to Žižlavský (2014) when it comes to NPV, an SME would prefer an existing ICT that generates a positive NPV, meaning a positive NPV will influence SME owners to accept continual usage of the existing ICT, while a negative NPV will make them consider adoption of an emerging ICT. When it comes to PBK, an SME owner will generally prefer an ICT that has a shorter pay-back period (PBK). A project with shorter payback period is considered as a better project because investors can recover the capital invested in a shorter period of time (Brigman and Cherry, 2002).

This study will apply both the PBK and the NPV to evaluate the financial value and risk of existing ICTs. The financial evaluation will directly influence the organisation to either keep on using existing ICTs, or to adopt emerging ICTs. Therefore, this study hypothesises that:

H13: FEM will impact on organisational factors in SME evaluation of existing ICTs.

\subsection{Conceptual Theoretical Framework}

After a review of the relevant financial and non-financial factors to evaluate an existing ICT, the paper developed the below conceptual framework with the hypothesised relationships to be investigated and validated.

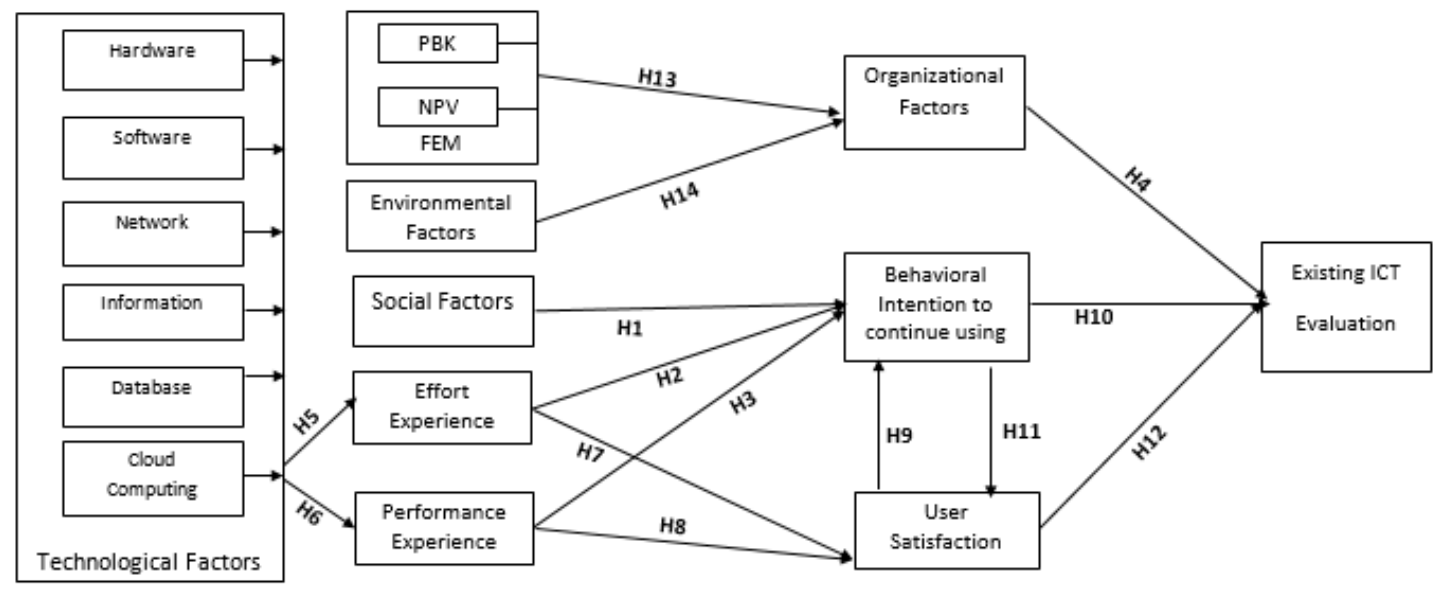

Figure 3: Conceptual Theoretical framework for technology evaluation 


\section{Methods}

Due to the difficulty in getting in touch with SME owners to administer the survey the study resorted to using an online survey closed-ended questionnaire developed using Google forms. The questions included in the questionnaire were adopted and operationalised from previous research studies (especially the ones reviewed). The questions were adopted from ISSM, UTAUT and financial model studies. The researcher only rephrased them to suit the current study. The online survey questionnaire was made available to clients via this link "(Online Survey Questionnaire)". A positivism philosophy and research instrument used for data collection paved way to the use of quantitative data analysis method. Therefore, the study collected data from 300 SME Owners whose SMEs are operating in South Africa regardless of their trade channel or line of business. Of the collected data, the study used 222 questionnaires as the rest were not usable giving a usable rate of $98.3 \%$ out of the 226 who had agreed to the consent to participate in the study. The 222 questionnaires were analysed using SPSS and AMOS software. SPSS was used to extract the reliability of the research instrument as well as for each construct. AMOS was used to conduct Structural Equation Modelling (SEM) in order to validate the developed model. The study followed the stages suggested by Hair (2006) when conducting SEM which are; developing measurement models, testing and assessing the measurement models for validity with the collected data, developing of the structure model, assessing structural model validity and finally extracting path values to assess supported and unsupported hypothesis.

\section{Results}

After sequentially following the stages suggested by Hair (2006) and after the structural model was found fit, the relationships that existed between constructs were then analysed, the study extracted both the refined measurement model and path values from AMOS. Figure 4 and table 1 below details the results.

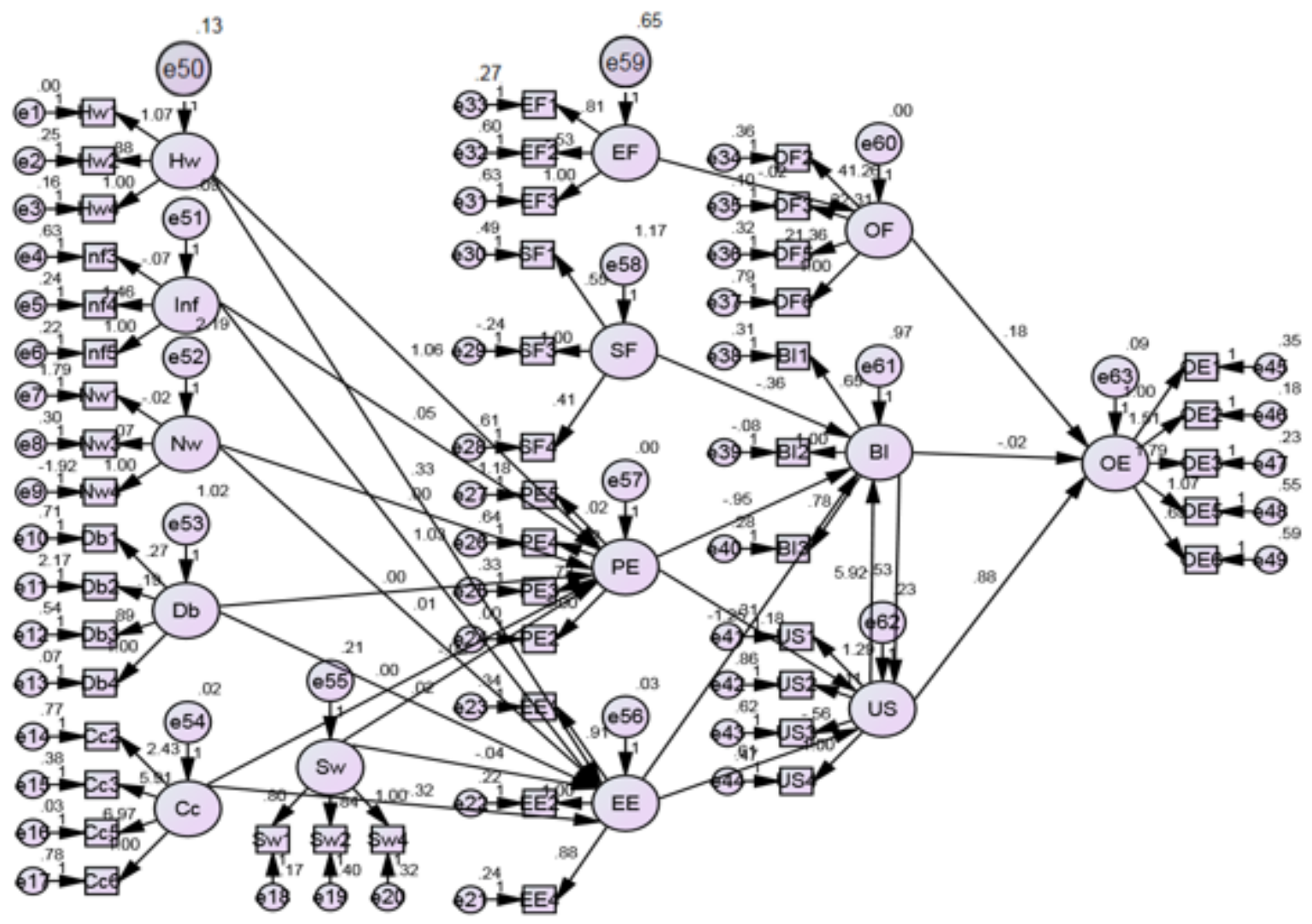

Figure 4: Refined Structural Model for evaluation of an existing Technology 
Table 1: Extracted Path values and summary of the Standardized Significance Levels of Constructs

\begin{tabular}{|c|c|c|c|c|c|c|c|c|}
\hline Hypothesis & $\mathrm{Pa}$ & & & Estimate & S.E. & C.R. & $\mathrm{P}$ & Comment \\
\hline $\mathrm{H} 1$ & $\mathrm{BI}$ & <--- & SF & -.358 & .170 & -2.107 & .035 & Hypothesis accepted \\
\hline $\mathrm{H} 2$ & BI & |<-- & $\mathrm{EE}$ & -1.246 & .818 & -1.523 & .128 & Hypothesis rejected \\
\hline H3 & BI & |<-- & PE & 181 & .080 & 2.269 & .023 & Hypothesis accepted \\
\hline $\mathrm{H} 4$ & $\mathrm{OE}$ & |<-- & OF & 175 & 1.240 & 141 & .888 & Hypothesis rejected \\
\hline H5a & $\mathrm{EE}$ & $\mid<--$ & $\mathrm{Hw}$ & .334 & .054 & 6.226 & $* * *$ & Hypothesis accepted \\
\hline $\mathrm{H} 5 \mathrm{~b}$ & EE & |<--- & Sw & -.045 & .074 & -.605 & .545 & Hypothesis rejected \\
\hline $\mathrm{H} 5 \mathrm{c}$ & $\mathrm{EE}$ & $\mid<--$ & $\mathrm{Nw}$ & .005 & .044 & 123 & .902 & Hypothesis rejected \\
\hline $\mathrm{H} 5 \mathrm{~d}$ & EE & |<-- & $\operatorname{lnf}$ & 1.035 & .215 & 4.820 & $* * *$ & Hypothesis accepted \\
\hline $\mathrm{H} 5 \mathrm{e}$ & EE & |<--- & $\mathrm{Db}$ & .017 & .028 & .624 & .533 & Hypothesis rejected \\
\hline H5f & EE & |<-- & Cc & -.319 & .237 & -1.345 & .179 & Hypothesis rejected \\
\hline H6a & PE & |<-- & $\mathrm{Hw}$ & 1.058 & .047 & 22.737 & $* * *$ & Hypothesis accepted \\
\hline $\mathrm{H} 6 \mathrm{~b}$ & PE & |<-- & Sw & -.025 & .012 & -2.008 & .045 & Hypothesis accepted \\
\hline $\mathrm{H} 6 \mathrm{c}$ & PE & |<--- & $\mathrm{Nw}$ & .002 & .013 & .124 & .901 & Hypothesis rejected \\
\hline $\mathrm{H} 6 \mathrm{~d}$ & PE & |<-- & $\operatorname{lnf}$ & .050 & .020 & 2.549 & .011 & Hypothesis accepted \\
\hline H6e & PE & $\mid<--$ & $\mathrm{Db}$ & -.001 & .004 & -.153 & .878 & Hypothesis rejected \\
\hline $\mathrm{H} 6 \mathrm{f}$ & PE & $\mid<--$ & Cc & -.003 & .031 & -.095 & .924 & Hypothesis rejected \\
\hline $\mathrm{H} 7$ & US & |<--- & $\mathrm{EE}$ & .609 & .259 & 2.354 & .019 & Hypothesis accepted \\
\hline $\mathrm{H} 8$ & US & |<-- & PE & 181 & .080 & 2.269 & .023 & Hypothesis accepted \\
\hline H9 & BI & |<--- & US & 5.922 & 2.329 & 2.543 & .011 & Hypothesis accepted \\
\hline $\mathrm{H} 10$ & $\mathrm{OE}$ & |<-- & $\mathrm{BI}$ & -.024 & .044 & -.560 & .576 & Hypothesis rejected \\
\hline $\mathrm{H} 11$ & US & $\mid<--$ & $\mathrm{BI}$ & -.534 & .347 & -1.537 & 124 & Hypothesis rejected \\
\hline $\mathrm{H} 12$ & $\mathrm{OE}$ & $<---$ & US & .877 & .243 & 3.607 & $* * *$ & Hypothesis accepted \\
\hline H13a & OF & $<--$ & PBK & & & & & Not included in SEM \\
\hline $\mathrm{H} 13 \mathrm{~b}$ & OF & $\mid<--$ & NPV & & & & & Not included in SEM \\
\hline H14 & OF & |<-- & $\mathrm{EF}$ & -.023 & .063 & -.364 & .716 & Hypothesis rejected \\
\hline
\end{tabular}

According to Hair (2006) for a hypothesis to be accepted the magnitude of its critical ratio (CR) should be above 1.96 whether positive or negative, while a rejected hypothesis' CR value is below 1.96. Results shown in Table 1 indicate that a good number of the suggested hypotheses $(\mathrm{H} 1, \mathrm{H} 3, \mathrm{H} 5 \mathrm{a}, \mathrm{H} 5 \mathrm{~d}, \mathrm{H} 6 \mathrm{a}, \mathrm{H} 6 \mathrm{~b}, \mathrm{H} 6, \mathrm{H} 7, \mathrm{H} 8, \mathrm{H} 9$ and $\mathrm{H} 12$ ) were accepted. This is so because their CR values were above \pm 1.96 ; their values being-2.107, 2.269, $6.226,4.820,22.737,-2.008,2.549,2.354,2.269,2.543$ and 3.607 respectively. On the other hand, hypotheses $\mathrm{H} 2, \mathrm{H} 4, \mathrm{H} 5 \mathrm{~b}, \mathrm{H} 5 \mathrm{c}, \mathrm{H} 5 \mathrm{e}, \mathrm{H} 5 \mathrm{f}, \mathrm{H} 6 \mathrm{c}, \mathrm{H} 6 \mathrm{e}, \mathrm{H} 6 \mathrm{f}, \mathrm{H} 10, \mathrm{H} 11, \mathrm{H} 13 \mathrm{a}, \mathrm{H} 13 \mathrm{~b}$ and $\mathrm{H} 14$ were rejected because their $\mathrm{CR}$ values were below the threshold of \pm 1.96 . Their values were $-1.523,0.141,-0.605,0.123,0.624,-1.345,0.124$, $-0.153,-0.095,-0.560,-1.537$ and -0.364 respectively, except for $\mathrm{H} 13 \mathrm{a}$ and $\mathrm{H} 13 \mathrm{~b}$.

Hypothesis $\mathrm{H} 13 \mathrm{a}$ and $\mathrm{H} 13 \mathrm{~b}$ were not included in SEM analysis due to violation of SEM assumptions and requirements. The NPV values were computed in monetary form, meaning the scale for NPV was different from the scale used for the other non-financial constructs that were based on the 5-Likert scale, therefore the study made an attempt to convert NPV and PBK to have the same scale as the rest of the constructs. In that endeavour because NPV could take two possible values negative NPV and positive NPV, the study decided to convert NPV into a dichotomous variable where by 1 would represent negative NPV and 2 would represent 
positive NPV. However, the NPV values for this study were all positive hence were coded with a value of 2 . This shows that after recoding to a dichotomous variable the two possible values were not well and evenly represented as 2 had 100\% representation while the option 1 had $0 \%$ representation. This is a challenge as noted by Hair (2006) and Kline (2004) that there is always a problem in conducting SEM when one group is over represented than the other due to imbalance of groups. Therefore, NPV was not included in SEM analysis. Due to the decision not to include NPV in SEM, it became difficult to include PBK even though PBK as a construct met all the assumptions for SEM. This is because ultimately the construct FEM would have one observable variable which is PBK since NPV was excluded. For a latent variable to be included in confirmatory analysis its observable variables should be at least two, otherwise three and more are preferable (Ding et al., 1995, Hair, 2006, Kline, 2004). Therefore, FEM could not be included in confirmatory analysis as it was left with a single observable variable (PBK).

After excluding the unsupported hypothesis a final model for evaluation of an existing ICT was developed. Figure 5 below summarises the final research model.

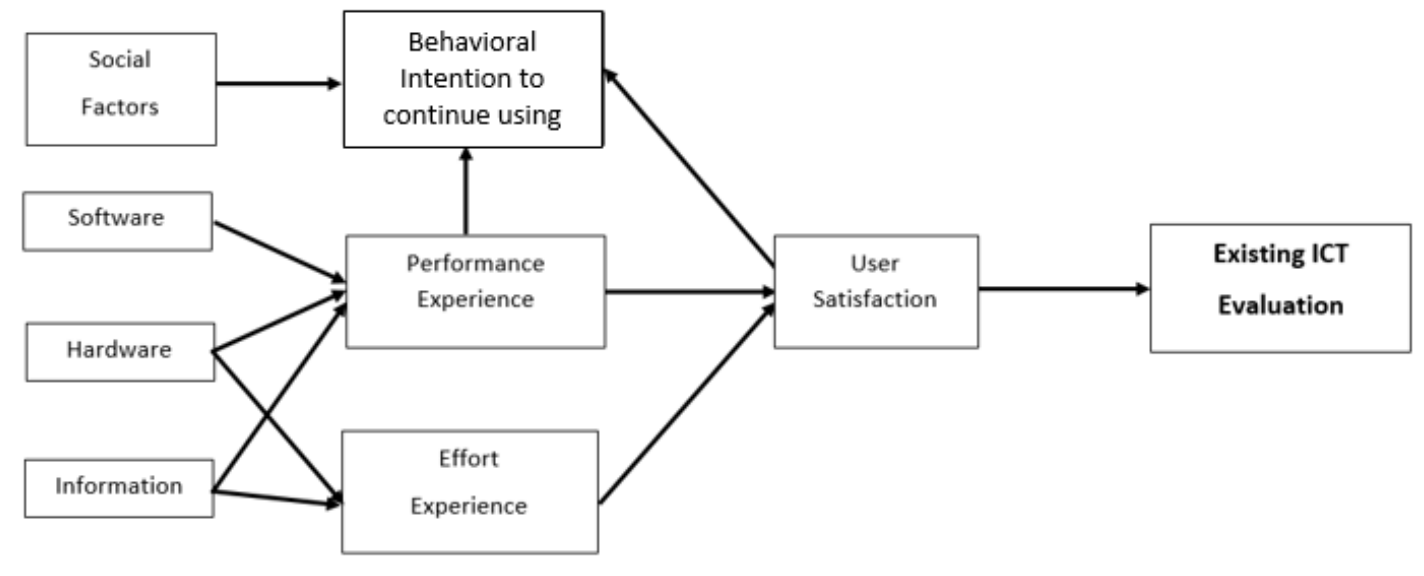

Figure 5: Modified ICT evaluation model (TEM)

\section{Discussion and contributions of findings}

Davis (1989), Mathieson (1991) and Lu et al. (2005) noted that when adoption of technology is voluntary social influences exert no direct impact on intention. It is imperative to note that that an SME owner has the power to either continue using the existing ICTs or to adopt new emerging ICTs. The continual usage of existing ICTs is thus voluntary and not mandatory. The SME owner, however, has no superior to gate his/her usage and thus his/her choice would be voluntary from the beginning to the end of the project life cycle. SME owners should thus consult with significant others to ascertain whether their existing ICTs are still useful, or not. Hence, when the user has no superior, the environment is always voluntary and social factors always play part. This study thus concluded that even in voluntary settings, social factors are an important role player during the evaluation of existing ICTs; the only difference is the circumstances, or type of user. The implication of this result is that SME owners should consult with significant others, who have been using the same ICTs as the ones they are currently using, to ascertain whether they should continue using the ICTs or whether they should adopt emerging ICTs. This will allow them to gain useful insights as to the worth of their existing ICTs.

The implications of this result is that SME owners should not base their decisions to continue using the existing ICTs on the effort experiences they have acquired. The experiences may deceive them to believe that the upcoming ICTs are better than the existing or vice versa. Therefore, the performance of existing ICTs matters more than how much users know about existing ICTs. However, the satisfaction of an SME owner as far as the amount of effort they expend on the existing ICTs is important in its evaluation. SME owners would prefer ICTS that require less effort to use.

When it comes to the performance experienced by the SME owners in using the existing ICTs, their experience will determine their behavioural intention to continue using the existing ICTs as well as their satisfaction with the existing ICTs. Once SMEs are satisfied and intend to keep using the existing ICTs, they are likely not to consider the emerging ICTs. 
ICT characteristics such as hardware, software and information were found to indirectly influence satisfaction and intentions to continue using the existing ICTs. They had a direct influence on performance experienced and effort experienced. This implies that, when SME owners are considering a switch between existing and emerging ICTs, there is no need to consider, the network infrastructure, databases and cloud computing facilities, rather the most important characteristics are hardware, software and information.

This result found out that, external and internal forces referred to as environmental and organisational factors in this study do not influence the decision of an SME owner to adopt emerging ICTs or keep using existing ICTs. This result concur with the social influence result obtained that, SME owners are the sole decision makers in the road to switch between emerging and existing ICTs and hence external and internal influences are not salient. Therefore, factors such as existence of technical and organisational infrastructure and competitive pressure are not important to SME owners.

Financial evaluation models were not conclusive as they failed to meet some SEM assumptions. Therefore, this study makes a contribution to SEM studies that during the preliminary stages of a study there is need to consider as many construct items as possible that surpasses the minimum of two suggested by literature. This will accommodate for elimination of invalid items to fit the model thereby allowing for each construct item to have two or more items. This study could therefore have started with six financial models and then stream them down to as little as two.

The concept of ICT evaluation is not new, however the tools that have been used by various stakeholders were not sufficient. It is paramount to note that the literature regarding the evaluation of existing ICTs within SMES is still scarce and limited. A large portion of writings surveyed apart from ICTs centered on other technological uses, acceptance, adoptions and evaluations in other environments. The literature was then contextualised to existing ICT evaluation in South African SMEs environment. The study has thus contributed to the IS body of knowledge by scoping a literature body specific to the evaluation of existing ICTs within SMEs in South Africa. Therefore, this literature could be used as a reference and starting point by IS researchers when conducting ICT evaluation studies in SMEs of other countries, or in non-SME environments. This study thus significantly contributes to the IS body of knowledge.

The study has contributed to new knowledge by developing an empirical model which can be used to study the evaluation of existing ICTs in SMEs, and other environments. Finally, the study has added to the very limited body of literature on ICT evaluation.

This research study was done within the South African SME environment. Hence, it is expected that the model developed will be used by South African SMEs in pursuing the evaluation of their existing ICTs before adopting any emerging ICTs. The same developed model could also assist SMEs in other countries to evaluate their existing ICTs. Other organisations (non-SMEs) can also use this model as a baseline to contextualise the evaluation of existing ICTs in their organisations. If this model is used by SMEs, it will likely help SME owners in making informed decisions as far as the evaluation of existing ICTs and adoption of emerging ICTs is concerned. As this model assists SMEs in the evaluation of existing ICTs it will, in turn, aid them in ensuring that they use the right ICTs at the right time. It thus enables them to evaluate whether the existing ICTs are useful or it might advise them to adopt emerging ICTs.

\section{Conclusions and future research}

The paper's objective was to develop a structural model for the evaluation of an existing ICT before adopting and switching to an emerging ICT. The paper started by reviewing from literature, the financial and nonfinancial factors that could be considered when evaluating an existing ICT. The identified factors were developed into an integrated conceptual framework represented in figure 3 that informed this study. Data was collected and analysed using structural equation model. Figure 5 shows the final refined structural model after achieving model fitness. Extracted path values showed that, the factors to consider in the final model for evaluation of existing ICT are; technological factors like hardware, information, software, social factors, performance experience, effort experience, behavioural intention to continue using and user satisfaction are the factors to consider when evaluating an existing ICT, while technological factors like Network, database, cloud computing, organisational factors and environmental factors are not important to include when 
evaluating existing ICT. The financial factors (NPV and PBK), were not conclusive as they were not included in SEM analysis.

Future research should consider doing a longitudinal study that allows more time for collection of data from a large number of SME Owners unlike 222 used in this study which others can classify as a small sample with respect to the total population of SME owners. More data might pave way for having an almost equal number of positive and negative NPV, thereby making NPV usable as a factor in SEM. Furthermore, even though literature suggested the use of two financial models, this is not good practice for SEM studies as more observable variables are recommended for good results in SEM than two. Therefore, SEM studies can use as many as four financial models. This will also address the unforeseen limitation met by this study in the case that one or two models fail to meet SEM limitations.

\section{References}

Ajzen, I., 1991. The theory of planned behavior. Organ behav hum dec 50: 179-211.

Alwahaishi, S. and Snásel, V., 2013. Acceptance and use of information and communications technology: A utaut and flow based theoretical model. Journal of Technology Management and Innovation, 8, pp. 61-73.

Bandura, A., 1986. Social foundations of thought and action, NJ, Prentice-Hall, Inc.

Bernroider, E. W., 2008. It governance for enterprise resource planning supported by the delone-mclean model of information systems success. Information \& Management, 45, pp. 257-269.

Bidgoli, H., 2011. MIS ${ }^{2}$, United States of America, Cengage Learning.

Bokhari, R. H., 2005. The relationship between system usage and user satisfaction: A meta-analysis. Journal of Enterprise Information Management, 18, pp. 211-234.

Brigman, S. and Cherry, K. E., 2002. Age and skilled performance: Contributions of working memory and processing speed. Brain and Cognition, 50, pp. 242-256.

Chaysin, P., Daengdej, J. and Tangitprom, N., 2016. Survey on available methods to evaluate it investment. Electronic Journal Information Systems Evaluation Volume, 19, pp. 71-82.

Cheah, P. K., Yap, Y. O., Unnithan, P., Moses, P., Diong, F. W. and Er, P. H. Factors leading to technology non-use in education: Validation of reversed-utaut ( $r$-utaut). Proceedings of the International Conference on e-Learning, 2014. pp. 39-44.

Cornacchia, M., Papa, F., Livi, S., Sapio, B., Nicolò, E. and Bruno, G. Factors affecting the usage of t-government services - an exploratory study. ICE-B 2008, 2008. pp. 315-322.

Cronje, J., 1990. Implications for teaching of a process-based research framework for information systems [Online]. Available: https://www.sites.google.com/site/johannescronje/roodeburrellmorgan [Accessed 30th May 2019.

Davis, F. D., 1989. Perceived usefulness, perceived ease of use, and user acceptance of information technology. Management Information Systems Quarterly, 13, pp. 319-340.

Davis, F. D., 1993. User acceptance of information technology: System characteristics, user perceptions and behavioral impacts. International Journal of Man-Machine Studies, 38, pp. 475-487.

DeLone, W. H. and McLean, E. R., 1992. Information systems success: The quest for the dependent variable. Information Systems Research, 3, pp. 60-95.

DeLone, W. H. and McLean, E. R. Information systems success revisited. Proceedings of the 35th Annual Hawaii International Conference on System Sciences, 2002. IEEE, pp. 2966-2976.

Delone, W. H. and McLean, E. R., 2003. The delone and mclean model of information systems success: A ten-year update. Journal of Management Information Systems, 19, pp. 9-30.

Ding, L., Velicer, W. F. and Harlow, L. L., 1995. Effects of estimation methods, number of indicators per factor, and improper solutions on structural equation modeling fit indices. Structural Equation Modeling: A Multidisciplinary Journal, 2, pp. 119-143.

Foon, Y. S. and Fah, B. C. Y., 2011. Internet banking adoption in kuala lumpur: An application of utaut model. International Journal of Business and Management, 6, pp. 161-167.

Gable, G. G., Sedera, D. and Chan, T., 2008. Re-conceptualizing information system success: The is-impact measurement model. Journal of the Association for Information Systems, 9, pp. 18.

Geisler, E. The metrics of technology evaluation: Where we stand and where we should go from here. 24th Annual Technology Transfer Society Meeting, 1999. pp.

Hair, J. F., 2006. Multivariate data analysis, India, Pearson Education India.

Im, I., Hong, S. and Kang, M. S., 2011. An international comparison of technology adoption: Testing the utaut model. Information and Management, 48, pp. 1-8.

Jiang, J. J., Klein, G. and Carr, C. L., 2002. Measuring information system service quality: Servqual from the other side. Management Information Systems Quarterly, 26, pp. 145-166.

Kalema, B. M. The role of moderating factors in erp systems usage. Third International Conference on Innovative Computing Technology (INTECH 2013), 2013. IEEE, pp. 166-172. 
Kim, S. H., Jang, S. Y. and Yang, K. H., 2017. Analysis of the determinants of software-as-a-service adoption in small businesses: Risks, benefits, and organizational and environmental factors. Journal of Small Business Management, 55, pp. 303-325.

Kline, R. B., 2004. Principles and practice of structural equation modeling (methodology in the social sciences). New York, NY: The Guilford Press.

Lefley, F., 1996. The payback method of investment appraisal: A review and synthesis. International Journal of Production Economics, 44, pp. 207-224.

Lefley, F., 2013. The appraisal of ict and non-ict capital projects: A study of the current practices of large uk organisations. International Journal of Managing Projects in Business, 6, pp. 505-533.

Ling, L. W., Downe, A. G., Ahmad, W. F. W. and Lai, T. T. Determinants of computer usage among educators: A comparison between the utaut and tam models. 2011 National Postgraduate Conference, 2011. IEEE, pp. 1-6.

Lu, J., Yao, J. E. and Yu, C. S., 2005. Personal innovativeness, social influences and adoption of wireless internet services via mobile technology. The Journal of Strategic Information Systems, 14, pp. 245-268.

Lyytinen, K. J. and Ngwenyama, O. K., 1992. What does computer support for cooperative work mean? A structurational analysis of computer supported cooperative work. Accounting, Management and Information Technologies, 2, pp. 19-37.

Maillet, É., Mathieu, L. and Sicotte, C., 2015. Modeling factors explaining the acceptance, actual use and satisfaction of nurses using an electronic patient record in acute care settings: An extension of the utaut. International journJl of Medical Informatics, 84, pp. 36-47.

Mathieson, K., 1991. Predicting user intentions: Comparing the technology acceptance model with the theory of planned behavior. Information Systems Research, 2, pp. 173-191.

McGill, T., Hobbs, V. and Klobas, J., 2003. User developed applications and information systems success: A test of delone and mclean's model. Information Resources Management Journal (IRMJ), 16, pp. 24-45.

Milis, K., Snoeck, M. and Haesen, R. 2009. Evaluation of the applicability of investment appraisal techniques for assessing the business value of is services. Available: Available at SSRN: https://ssrn.com/abstract $=1517656$ or http://dx.doi.org/10.2139/ssrn.1517656 [Accessed 30-05-2019].

Nirban, V. S. New media technology acceptance by students of undergraduate language and communication courses. 2014 IEEE International Conference on MOOC, Innovation and Technology in Education (MITE), 2014. IEEE, pp. 62-66.

Noorman, M. M., Shahriza, A. K. N. and Hussein, R., 2007. Investigating corporate intranet effectiveness: A conceptua framework. Information Management \& Computer Security, 15, pp. 168-183.

Odhiambo, C. J. 2016. Response strategies adopted by public benefit organizations in kisumu county, kenya to changes in the competitive environment. Available:

http://erepository.uonbi.ac.ke/bitstream/handle/11295/98997/Odhiambo Response\%20Strategies\%20Adopted\%20 By\%20Public\%20Benefit\%20Organizations\%20In\%20Kisumu\%20County\%2C\%20Kenya\%20To\%20Changes\%20In\%20T he\%20Competetive\%20Enviromen.pdf?sequence=1\&isAllowed=y [Accessed 2017-10-10].

Oliveira, T., Faria, M., Thomas, M. A. and Popovič, A., 2014. Extending the understanding of mobile banking adoption: When utaut meets ttf and itm. International Journal of Information Management, 34, pp. 689-703.

Orlikowski, W. J. and lacono, C. S., 2001. Research commentary: Desperately seeking the "it" in it research - a call to theorizing the it artifact. Information Systems Research, 12, pp. 121-134.

Oye, N., lahad, N. and Rahim, N. A., 2014. The history of utaut model and its impact on ict acceptance and usage by academicians. Education and Information Technologies, 19, pp. 251-270.

Pardamean, B. and Susanto, M., 2012. Assessing user acceptance toward blog technology using the utaut model. International Journal of Mathematics and Computers in Simulation, 1, pp. 203-212.

Park, J., Yang, S. and Lehto, X., 2007. Adoption of mobile technologies for chinese consumers. Journal of Electronic Commerce Research, 8, pp. 196-206.

Petter, S., DeLone, W. and McLean, E., 2008. Measuring information systems success: Models, dimensions, measures, and interrelationships. European Journal of Information Systems, 17, pp. 236-263.

Petter, S. and McLean, E. R., 2009. A meta-analytic assessment of the delone and mclean is success model: An examination of is success at the individual level. Information and Management, 46, pp. 159-166.

Pitt, L. F., Watson, R. T. and Kavan, C. B., 1995. Service quality: A measure of information systems effectiveness. Management Information Systems Quarterly, 19, pp. 173-187.

Rappaport, A., 1965. The discounted payback period. Management Services, 2, pp. 30-36.

Roca, J. C., Chiu, C.-M. and Martínez, F. J., 2006. Understanding e-learning continuance intention: An extension of the technology acceptance model. International Journal of Human-Computer Studies, 64, pp. 683-696.

Seddon, P. B., 1997. A respecification and extension of the delone and mclean model of is success. Information Systems Research, 8, pp. 240-253.

Tan, P. J. B., 2013. Students' adoptions and attitudes towards electronic placement tests: A utaut analysis. American Journal of Computer Technology and Application, 1, pp. 14-23.

Teece, D. J., Pisano, G. and Shuen, A., 1997. Dynamic capabilities and strategic management. Strategic Management Journal, 18, pp. 509-533.

Thompson, R. L., Higgins, C. A. and Howell, J. M., 1991. Personal computing: Toward a conceptual model of utilization. Management Information Systems Quarterly, 15, pp. 125-143. 
Trimmer, K., Beachboard, J., Wiggins, C. and Woodhouse, W. Electronic medical records use an examination of resident physician intentions. Proceedings of the 41st Annual Hawaii International Conference on System Sciences (HICSS 2008), 2008. IEEE, pp. 249-249.

Venkatesh, V. and Davis, F. D., 2000. A theoretical extension of the technology acceptance model: Four longitudinal field studies. Management Science, 46, pp. 186-204.

Venkatesh, V. and Morris, M. G., 2000. Why don't men ever stop to ask for directions? Gender, social influence, and their role in technology acceptance and usage behavior. Management Information Systems Quarterly, 24, pp. 115-139.

Venkatesh, V., Morris, M. G., Davis, G. B. and Davis, F. D., 2003. User acceptance of information technology: Toward a unified view. Management Information Systems Quarterly, 27, pp. 425-478.

Wang, C. L. and Ahmed, P. K., 2007. Dynamic capabilities: A review and research agenda. International Journal of Management Reviews, 9, pp. 31-51.

Wang, Y.-S. and Liao, Y.-W., 2008. Assessing egovernment systems success: A validation of the delone and mclean model of information systems success. Government Information Quarterly, 25, pp. 717-733.

Xiao, X., Califf, C. B., Sarker, S. and Sarker, S., 2013. Ict innovation in emerging economies: A review of the existing literature and a framework for future research. Journal of Information Technology, 28, pp. 264-278.

Yu, C.-S., 2012. Factors affecting individuals to adopt mobile banking: Empirical evidence from the utaut model. Journal of Electronic Commerce Research, 13, pp. 104-121.

Zhou, T., 2011. Understanding mobile internet continuance usage from the perspectives of utaut and flow. Information Development, 27, pp. 207-218.

Zhou, T., Lu, Y. and Wang, B., 2010. Integrating ttf and utaut to explain mobile banking user adoption. Computers in Human Behavior, 26, pp. 760-767.

Žižlavský, O., 2014. Net present value approach: Method for economic assessment of innovation projects. Procedia-Social and Behavioral Sciences, 156, pp. 506-512. 